THE JOURNAL OF TRANSPORT AND LAND USE http://jtlu.org

vol. 5 No. 3 [2012] pp. 53-67 doi: 10.5198/jtlu.v5i3.247

\title{
Does public transit use enhance the economic efficiency of urban areas?
}

\author{
Matthew P. Drennan ${ }^{a}$ \\ UCLA
}

\author{
Charles Brecher ${ }^{\mathrm{b}}$ \\ New York University
}

\begin{abstract}
This paper explores the relationship between the scale of public transit services in large urban areas of the United States and the efficiency of those economies, with efficiency measured by commercial office rents. Panel regressions are estimated in which real office rent is the left-hand variable. The key right-hand variable is per-capita transit use. Other right-hand variables include demand for office space, office vacancy rate, average real wage, and unemployment rate. Two-stage least-squares equations are estimated to deal with possible simultaneity between office rents and transit use. Results indicate a positive relationship between public transit use and office rents. The relationship is positive and significant in urban areas with higher concentrations of office space in the central business district, and nonexistent in urban areas with lower concentrations. The estimated dollar impact of transit use on office rents is small.
\end{abstract}

\section{Introduction}

A variety of arguments are made to support public investment in mass transit. Some relate to its environmental advantages over auto use (Owen 2009), and these arguments have some scientific evidence supporting them. Other arguments relate to the benefits of mass transit in making urban economies more efficient by enhancing employer access to a larger labor pool at lower transport costs. That, however, is too narrow a view of economic efficiency of an urban area. As first described by Alfred Marshall (1920), there are three efficiency gains from the concentration of economic activities in urban areas, referred to as urban agglomeration economies. They are (1) the pooling of labor, (2) input sharing, and (3) knowledge spillovers among firms. Urban agglomeration economies are external economies. That is, they are external to the firm and arise from proximity. Over the past few decades, a large body of urban economics literature has developed that attempts to measure agglomeration economies by their effect on productivity, wages, urban growth, and entrepreneurship (Rosenthal and Strange 2004). Other factors being controlled for, the presence of urban agglomeration economies is hypothesized to raise productivity, wages, growth, and entrepreneurship - that is, to improve urban efficiency.

Because it is not possible to directly observe the presence of urban agglomeration economies, the usual proxies to represent them in an estimating equation are urban population or density, total employment or specific industry employment, patents, or research and development expenditures in the urban area. "[H]igh productivity, employment, wages and rents reflect the presence of agglomeration economies" (Rosenthal and Strange 2004, p. 2147). Economic theory asserts that higher productivity or higher wages reflect greater efficiency. Thus, if productivity or wages in an urban area are higher than elsewhere after accounting for usual supply and demand factors, then that efficiency gain may be attributed to the presence of unobserved urban agglomeration economies.

Few studies have utilized high rents to reflect the presence of agglomeration economies and thus increased economic efficiency. Most have used labor productivity or wages (see review article by Eberts and McMillen 1999). Given that capital as well as labor is an input in production, the return to capital should reflect economic efficiency of an urban area just as wages do. In modern large metropolitan areas, a great deal of the employment is in office activities, particularly producer services. For 40 years or more, the share of metropolitan employment in goods production and distribution (manufacturing, mining, wholesale trade, and transportation) has been in decline, while the share in producer services (finance and insurance, information, and business services) has been rising. Part of the reason for that shift is that the urban agglomeration economies gained by goods production and distribution firms in large metropolitan areas have declined or disappeared (Drennan 2002). The major capital input of the producer services sector is office space. We chose not to use wages or productivity or total output as our measure of efficiency because they are too

amattd@ucla.edu

b charles.brecher@nyu.edu 
broad and include economic sectors in relative or even absolute decline. We chose office rents rather than residential rents or residential land values because office rents reflect the return to a key capital input in urban production, namely, commercial office space. House rents or values do not directly reflect value added in urban production, but office rents do. If public transit makes areas more efficient by promoting economic benefits of agglomeration, then such benefits should be evident in expanding sectors of the local economy, namely, producer services. Hence we use office rents as our left-hand measure of the presence (or absence) of urban agglomeration economies. Just as the presence of urban agglomeration economies should be reflected in higher wages, ceteris paribus, their presence should be reflected in higher commercial office rents.

Our hypothesis is that urban economic efficiency, measured by commercial office rents, is enhanced by the scale of public transit use. Put another way, urban economies of agglomeration are promoted by the scale of public transit use. Our reasoning is that two of Marshall's three efficiency gains (labor pooling and knowledge spillovers) appear more likely to occur if the transit infrastructure facilitates a much greater concentration of economic activities in space than would be feasible without a large-scale transit system.

Office rents, as an indicator of efficiency gains from the presence of urban agglomeration economies, can be hypothesized to be higher in areas better served by mass transit for multiple reasons. Most frequently noted are the labor market efficiencies. The possibility for massive concentrations of highly skilled workers in a limited area enhances the likelihood of agglomeration economies of two types: labor pooling and knowledge spillovers. Because high public transit use makes such concentrations possible, it increases the likelihood of agglomeration economies. As argued by Drennan and Kelly (2011), the presence of agglomeration economies raises rents.

More workers can reach a location at lower transportation costs (including time costs) when public transit serves that location. The benefits may be greater for less skilled and lower wage workers, because they may not be able to afford the option of commuting by auto. However, gains may also be evident for higher skilled workers and professionals who may prefer suburban residences but make use of available commuter railroads and other mass transit services rather than autos in order to save time, make more productive use of commuting time by reading, and avoid the frustrations of unpredictable traffic patterns. More recently, as concerns among young professionals and others have grown over the links between auto use and contributions to global warming, urban areas with more extensive mass transit services may be more attractive to these creative young workers.
In the next section we review the literature on the effect of public transit on land values or rents in urban areas. In section three we describe the office markets and public transit characteristics of the metropolitan areas included in our sample. Following that, we present our panel regression model and the data used to estimate it. Results are presented in section five, along with some insights from our results, and we conclude in section six.

\section{$2 \quad$ Literature review}

Much of the literature relating transit services to urban economic characteristics focuses on the relationship between accessibility of transit services and property values. That is, accessibility to transit services can raise (or lower) the value of commercial and residential property. While these studies consider the impact on specific locations within a region rather than the efficiency of an overall urban area, they are instructive for considering the efficiency issue.

A recent meta-analysis of studies of the impact of railway stations on property values found the impact to vary based on three major factors (Debrezion, Pels and Rietveld 2007). First, the characteristics of the stations themselves vary. Commuter stations have a greater impact than other modes; stations with higher levels of service and facilities (including parking spaces) have a greater impact, and stations closer to the central business district (CBD) have a greater impact. The latter finding is particularly relevant to our hypothesis, although the data related to residential values. (Bowes and Ihlanfeldt 2001).

Second, the impact differed between residential and commercial properties. More empirical studies focus on residential properties, and they find the impacts to extend farther than for commercial property. The studies of commercial properties find the positive impact limited to adjacent areas, but to be stronger in those areas than for residential properties. However, one study in California found a negative impact on commercial property (Landis et al. 1995). The more general pattern of significant impacts on commercial property is consistent with the hypothesis that transit use improves urban efficiency.

Third, the literature suggests that the impact on property values varies with demographic characteristics. Specifically, residential values increase more in lower-income neighborhoods than in higher-income neighborhoods. The reason is that lower-income residents are more dependent on mass transit than auto-owning higher-income residents.

Only a few studies have examined the effects of public transit on commercial rents. These studies relate to specific metropolitan areas and to the effects of transit stations on surrounding buildings. For example, a study of Santa Clara Coun- 
ty in California uses a hedonic price model to measure the effect on land values of proximity to rail stations and freeway exits (Cervero and Duncan 2002a). It found significant positive effects on land values of proximity to both rail stations and freeway exits. An opposite conclusion was reached in a study of the San Francisco area, in which lease rates and occupancy rates of commercial buildings were related to distance from BART (Bay Area Rapid Transit) rail stations (Landis and Loutzenheiser 1995). The study regressed asking rents of individual buildings on building variables, market variables, and distance rings from BART stops. Posing the question of whether such proximity enhances the attractiveness of a property to office tenants, the answer was "no." "The fact that no such premiums are evident in the marketplace suggests that office agglomeration economies may not be as important as commonly supposed" (Landis and Loutzenheiser, p. 23). That is too strong a conclusion; the absence of a discernible BART effect does not rule out agglomeration economies. Rather it may mean that the highly skilled, highly productive workers drive, or walk, or use public transit other than BART (e.g., buses or streetcars).

A study of rail transit service in Los Angeles focused on land values for different classes of property (residential, commercial, etc.) and developed a hedonic price model to determine if property values are enhanced by proximity to rail stops (Cevero and Duncan 2002b). The study concluded, "While some instances of land value premiums were found, overall impacts were uneven and inconsistent" (p. 1). Although their models, one for each property type, have about 60 variables, the authors do not report adjusted $\mathrm{R}^{2}$ values for their estimated equations. The same authors conducted a similar study of rail transit services in San Diego County (Cervero and Duncan 2002c). They found that for commercial properties downtown and in one rail corridor, there were significant positive capitalization effects of rail transit service. However, in other locations commercial property gains were small to nonexistent to negative.

One study that influenced our inquiry was an analysis of rail transit on development in Atlanta and Washington, DC (Cervero 1994). The author concludes, "Among the dependent variables studied, the average office rent variable was more closely correlated with more transit factors than any of the [other] dependent variables. The strongest relationship was between office rents and ridership. Of particular note, office rents were more strongly influenced by transit ridership than by nearby freeway traffic volumes" (p. 11).

A sophisticated econometric study of office rents in the Atlanta MSA used individual office buildings as observations (Bollinger et al. 1998). Concentrations of professional workers in census tracts where office buildings were located were used to represent opportunities for face-to-face meetings. Interestingly, the authors found that such professional worker concentrations turned out to be "... among the strongest predictors of office rents" (p. 1, 112). The effect of the professional worker concentration variable on office rents for buildings in the CBD was four times larger than its effect in the suburbs. That corresponds to a recent study of office rents in 49 metropolitan areas where producer service employment proved to be a positive and significant variable in determining office rents (Drennan and Kelly 2010).

In contrast, the Bollinger et al paper found negative effects on office rents of train stations' proximity to office buildings, while the effect of highway exchanges' proximity was positive. Although their results do not support a positive effect of public rail transit on office rents, their professional employment concentration variable is similar to the use of producer service employment as a determinant of office rents in the paper by Drennan and Kelly (2011).

The last paper in this review is an analysis of transit ridership that takes into account the interdependence between transit demand and transit supply (Taylor et al. 2009). Utilizing a data set of 265 urbanized areas, two-stage least-squares crosssection regression equations are estimated to avoid the classic problem of regressing two simultaneously determined variables, demand and supply, on each other. Although the paper does not address the possible link between commercial office rents and public transit demand, it is germane to our analysis in its treatment of simultaneously determined variables and in its focus on transit fares. The authors conclude, "Controlling for the fact that public transit use is strongly correlated with urbanized area size, 26 percent of observed variance in per-capita transit patronage... is explained by service frequency and fare levels" (Taylor et al, p. 60). An omission in that paper is the issue of parking. Driving is a substitute for public transit use, and the appeal of driving is linked to the availability of and price for parking. Unfortunately, no good measures for the parking variable are available, so it is an omission from this paper as well.

\section{Description of sample}

Our sample is drawn from a merger of real estate data from Torto Wheaton Research (TWR) and public transit data from the National Transit Database (NTD), plus government sources for data on population, employment, and price deflators. The real estate market data provided by Torto Wheaton Research (TWR) cover 120 major commercial real estate markets in 52 metropolitan statistical areas (MSAs). Periodically, TWR adds new markets to its database, which begins in 1987 . We did not include those new markets in order to have the same 
set of places over the 21-year period, 1987-2007. All of the TWR data used is for the fourth quarter of the year indicated. The TWR variables for each of the 120 markets are averages or totals for the office buildings. The variables for each market and each year are annual average gross rents per square foot of commercial office space, the supply of space in millions of square feet, and the vacancy rate. Each of the 120 TWR real estate markets includes at least one million square feet of office space. If there are only two real estate markets in a metropolitan area, TWR designates the traditional downtown market as the central business district (CBD) and the other as suburban. If there are more than two, then the non-CBD markets are given geographical names. For example, the New York-Newark-Nassau Suffolk urbanized area UZA has 11 real estate market areas. (An urbanized area differs from a metropolitan statistical area (MSA) in that it does not necessarily include whole counties but rather, only those parts of counties that have a population density that meets the census's minimum threshold for being classified as urbanized.) TWR designates the CBD as midtown Manhattan. The 10 non-CBD markets are named for their specific geographic areas, one or more contiguous counties, or in one case, downtown Manhattan (namely, Wall Street). They include six markets in New Jersey (Morris-Hunterdon, Newark, Bergen-Passaic, Jersey City, Somerset, and MonmouthOcean) and four in New York (Nassau, Suffolk, Westchester, and downtown Manhattan).

The NTD annual data are organized by transit agency and grouped by census UZA. Among a host of variables, the NTD collects data by transit agency on the annual volume of passengers, annual passenger miles traveled, annual revenue miles of service, and annual fare revenues. We opted to use annual passengers per capita as a measure of transit use. This is a measure of trips rather than miles of use or service offered. Arguably, the alternative measures better reflect transit capacity and use, although the trip measure is more meaningful in the sense that it reflects individuals' decisions to use mass transit as opposed to other modes. Future research should explore the sensitivity of results to alternative measures of service use and capacity, but we restrict the analysis to the passenger trip measure of service use. The trip variable is additive for transit agencies within an urban area, so we were able to compute the annual totals by UZA from the reported data by agency. We did not use the individual transit agency data because geographical service areas of any agency do not correspond with our TWR real estate market areas. Instead, we consolidated service of all transit agencies within a UZA. The annual count of passengers is available from 1991 forward.

To make the two data sets geographically consistent, we combined some TWR MSAs to conform to the census defini- tions of UZAs. For example, Dallas and Fort Worth are separate MSAs in the TWR data, each with its own CBD. The census defines Dallas-Fort Worth as one UZA, so we followed that definition. Similarly, we combined TWR data for New York, Newark, and Nassau-Suffolk into one UZA with one CBD. Table 1 lists the UZAs included in our sample. We changed the TWR definition of the New York MSA CBD from midtown Manhattan to midtown plus downtown (i.e., Wall Street), in accordance with real estate industry practice.

In addition to those TWR real estate variables and NTD transit variables, we added metropolitan area-wide variables for the UZAs in which the office markets are located. Annual MSA population data are from the US Census Bureau. We did not use census UZA population data because it is only available for decennial census years. Total employment as well as employment in each of three North American Industry Classification System (NAICS) sectors-information, finance and insurance, and professional and business services-is from the Bureau of Labor Statistics (BLS) nonagricultural employment series. The sum of those three sectors we define as producer service employment. Because the BLS data on a NAICS basis goes back only to 1990 , we lack that measure of producer service employment for the three earliest years: 1987-1989. The dollar measure — office rents - has been adjusted for inflation by the GDP price index converted to a base of $2007=100$.

Examining the TWR dataset, we found two markets inappropriate for comparison. These markets were Edison, NJ, and Oxnard, CA—small and almost exclusively suburban markets at the peripheries of the New York City and Los Angeles conurbations, respectively. We dropped Edison, NJ, from our sample and added the Oxnard market to the Los Angeles area. The Long Island, NY, MSA was amalgamated into the New York MSA, in accordance with real estate industry practice. The Long Island MSA consists of Nassau and Suffolk Counties and defines the suburban office market immediately east of New York City.

Our final sample is 42 UZAs containing 118 real estate markets over 17 years (1991-2007). We dropped the 19871990 period because the transit use variable, central to this analysis, is available only back to 1991 . Because metropolitan areas are now polycentric, we require that our sample data include at least two real estate markets in each UZA. To analyze differences within UZAs, our observations are the 118 real estate markets, not the UZAs that contain them. If we used the UZAs as the unit of observation, we could not explore differences among real estate markets within a UZA. The relative efficiency as reflected in rents of the core central business district of each UZA over the 17-year period is our major concern. One and only one real estate market in a UZA is designated as 
the CBD in our analysis. All but one-Riverside, Californiaof our 42 UZAs has a CBD designated by the TWR data. The label is not arbitrary but conforms to real estate data usage.

Note that our sample data are for two different spatial units. The TWR real estate data are for 118 real estate markets within 42 UZAs. The NTD transit data are for the 42 UZAs. One might argue that the 118 real estate markets should be merged by UZA (each UZA has at least two real estate markets). That would conform to previous studies of urban economies of agglomeration, where all variables are for the entire metropolitan area. But as noted above, we view that as a flaw in earlier studies because it rules out the possibility of identifying differences in agglomeration economies-our measure of efficiency-within metropolitan areas. The fact that our transit data are for an entire metropolitan area (that is, a regional system), makes it possible to discern differences between CBD real estate markets and non-CBD real estate markets in terms of efficiency gains (or their absence). If our sample real estate markets were aggregated to the UZA level we would not be able to search for differences, if any, in the efficiency effects of a regional transit system on sub-parts of the region served.

The 118 real estate markets in our sample are the largest such markets in the United States. Each one has at least one million square feet of commercial office space. They are all within the boundaries of the 42 UZAs and they do not overlap. Of course, not every office building in a UZA is within the boundaries of a distinct TWR real estate market. Nonetheless, the TWR data captures the lion's share of commercial office space in the nation. The aggregate volume of those 42 UZAs is 3.4 billion square feet of net rentable office space in 2007. A real estate trade association, the Society of Industrial and Office Realtors, estimated the size of the national market at 3.92 billion square feet in 2003 (Kelly 2003).

We partition the total sample into CBD real estate markets and suburban markets. There is only one CBD in each of the 42 UZAs; all the non-CBD markets are labeled as "suburban." Every UZA has one or more suburban real estate markets, although they may not literally be suburban. For example, in the Los Angeles-Orange-Oxnard UZA, the CBD is downtown Los Angeles. One of the suburban real estate markets is Beverly Hills plus Century City, another is the San Fernando Valley. Those are decidedly urban areas within the city of Los Angeles, but they are distinct from the $\mathrm{CBD}$ among real estate professionals.

The simple mean ratio of $\mathrm{CBD}$ office space to total office space in the UZAs is 31.7 percent.

Table 1 ranks the 42 UZAs by size. The relevant size variable is not population but square feet of office space. The first of the three groups in Table 1 is areas with at least 70 million square feet of space. Among these areas, the shares of total office space in the CBD range from 66 percent in New York to 13 percent in Los Angeles and Miami. About half of those 14 places have rail transit systems - some extensive, some not. These 14 UZAs account for 72 percent of the space in all 42 UZAs. Note that many of the places with more than 70 million square feet have high concentrations of space in the CBD. A rule of thumb seems to be that cities that were large before the advent of the automobile (such as New York, Chicago, Boston, and San Francisco) have much higher concentrations of space in the CBD than post-automobile cities such as Los Angeles, Dallas, Miami, and Houston. The pre-automobile large cities tend to have extensive rail transit systems. However, they also have built environments that act as de facto pricing systems that boost the cost of driving. The supply of public transit matters, but so does the price of its substitute: driving.

Is concentrated development, a precondition for the emergence of urban agglomeration economies, facilitated by public transit? It is hard to say, but the descriptive evidence of Table 1 suggests such to be the case. The three largest UZAs after New York, in terms of total office space, are similar in total size: Washington, DC (270 million), Los Angeles (248 million) and Chicago (219 million). However, they are dramatically different in the absolute concentration of space in the CBD. Washington, DC, and Chicago have well-developed and well-used transit systems, while Los Angeles does not. The fifth and sixth largest commercial real estate metropolitan areas, Dallas (166 million) and Boston (158 million), are almost equal in total size, but the Boston CBD has three times as much office space as the Dallas CBD. Again, Boston has a heavily utilized transit system while Dallas does not (see Table 2). It may well be that commuting by private automobile places an effective de facto cap on how much office space can be accommodated in the $\mathrm{CBD}$ of a region.

Table 2 ranks the 42 UZAs by public transit use and shows the percent of journeys to work by public transit. Percapita transit use (the count of annual passengers divided by the metropolitan population) varies enormously among the 42 UZAs, from 215 in New York to less than 6 in Indianapolis and Riverside. In only five places do journeys to work via mass transit exceed 10 percent. New York is first at 31 percent, followed by San Francisco, Boston, Washington, DC, and Chicago - all in the mid- to low teens. Note that those five places' absolute concentration of space in their CBDs ranges from 362 million (New York) to 59 million (San Francisco), far exceeding any other metropolitan area.

The data in Tables 1 and 2 suggest a positive connection between the concentration of office space in CBDs and the use of public transit. We suspect that high public transit use 
Table 1: Office space in 42 UZAs, 2007.

\begin{tabular}{|c|c|c|c|c|}
\hline & CBD & SUB & Total Space & \\
\hline \multirow[t]{2}{*}{ UZA } & Space 2007 & Space 2007 & 2007 & CBD/Total \\
\hline & (Mil sq. ft.) & (Mil sq. ft.) & (Mil sq. ft.) & (\%) \\
\hline \multicolumn{5}{|l|}{ Places with more than 70 mil. sq. $\mathrm{ft}$. } \\
\hline New York-Newark-Nassau Suffolk & 362.0 & 183.5 & 545.5 & $66.4 \%$ \\
\hline Washington & 95.6 & 174.8 & 270.4 & $35.4 \%$ \\
\hline Los Angeles-Orange-Oxnard & 33.5 & 214.5 & 248.0 & $13.5 \%$ \\
\hline Chicago & 123.3 & 96.0 & 219.3 & $56.2 \%$ \\
\hline Dallas-Fort Worth & 25.6 & 140.0 & 165.6 & $15.5 \%$ \\
\hline Boston & 79.4 & 78.2 & 157.6 & $50.4 \%$ \\
\hline Houston & 35.2 & 102.1 & 137.3 & $25.6 \%$ \\
\hline San Francisco-Oakland & 59.1 & 77.7 & 136.8 & $43.2 \%$ \\
\hline Atlanta & 29.3 & 99.5 & 128.8 & $22.7 \%$ \\
\hline Philadelphia-Wilmington & 35.8 & 80.3 & 116.1 & $30.8 \%$ \\
\hline Miami-Fort Lauderdale & 12.5 & 84.1 & 96.6 & $12.9 \%$ \\
\hline Denver & 23.6 & 64.9 & 88.5 & $26.7 \%$ \\
\hline Seattle & 39.9 & 39.3 & 79.2 & $50.4 \%$ \\
\hline Detroit & 11.2 & 60.1 & 71.3 & $15.7 \%$ \\
\hline \multicolumn{5}{|l|}{ Places with 35 to 70 mil. sq. ft. } \\
\hline Phoenix & 14.2 & 53.8 & 68.0 & $20.9 \%$ \\
\hline Minneapolis & 29.2 & 34.7 & 63.9 & $45.7 \%$ \\
\hline San Diego & 9.8 & 45.0 & 54.8 & $17.9 \%$ \\
\hline Baltimore & 12.0 & 39.1 & 51.1 & $23.5 \%$ \\
\hline Kansas & 15.3 & 31.9 & 47.2 & $32.4 \%$ \\
\hline Sacramento & 8.3 & 33.8 & 42.1 & $19.7 \%$ \\
\hline Portland & 15.9 & 25.8 & 41.7 & $38.1 \%$ \\
\hline St Louis & 12.3 & 27.2 & 39.5 & $31.1 \%$ \\
\hline Charlotte & 13.9 & 25.4 & 39.3 & $35.4 \%$ \\
\hline Cleveland & 19.0 & 18.3 & 37.3 & $50.9 \%$ \\
\hline San Jose & 7.9 & 29.3 & 37.2 & $21.2 \%$ \\
\hline Tampa & 7.1 & 29.7 & 36.8 & $19.3 \%$ \\
\hline \multicolumn{5}{|l|}{ Places with less than 35 mil. sq. ft. } \\
\hline Austin & 8.2 & 26.0 & 34.2 & $24.0 \%$ \\
\hline Cincinati & 13.2 & 20.8 & 34.0 & $38.8 \%$ \\
\hline Orlando & 7.2 & 25.3 & 32.5 & $22.2 \%$ \\
\hline Stamford & 16.5 & 16.0 & 32.5 & $50.8 \%$ \\
\hline Indiannapolis & 11.7 & 19.0 & 30.7 & $38.1 \%$ \\
\hline Columbus & 11.3 & 19.0 & 30.3 & $37.3 \%$ \\
\hline Nashville & 6.6 & 23.0 & 29.6 & $22.3 \%$ \\
\hline Las Vegas & 1.6 & 27.9 & 29.5 & $5.4 \%$ \\
\hline Salt Lake City & 9.6 & 18.9 & 28.5 & $33.7 \%$ \\
\hline Hartford & 7.9 & 18.4 & 26.3 & $30.0 \%$ \\
\hline West Palm Beach & 12.2 & 11.9 & 24.1 & $50.6 \%$ \\
\hline Riverside & 0.0 & 21.6 & 21.6 & $0.0 \%$ \\
\hline Jacksonville & 7.8 & 12.6 & 20.4 & $38.2 \%$ \\
\hline Albuquerque & 2.9 & 9.2 & 12.1 & $24.0 \%$ \\
\hline Honolulu & 9.0 & 2.6 & 11.6 & $77.6 \%$ \\
\hline Tuscon & 1.2 & 6.8 & 8.0 & $15.0 \%$ \\
\hline All UZAs, Sums \&Simple Average & $1,257.8$ & $2,168.0$ & $3,425.8$ & $31.7 \%$ \\
\hline
\end{tabular}


Table 2: Annual count of UZA transit passenger trips per capita, 2007, and public transit travel to work, 2000 (ranked high to low by passenger trips per capita).

\begin{tabular}{|c|c|c|}
\hline \multirow[t]{2}{*}{ UZA } & Per Capita Passenger & Percent to Work by \\
\hline & Trips, 2007 & Public Transit, 2000 \\
\hline \multicolumn{3}{|c|}{ Places with more than 40 passenger trips per capita } \\
\hline New York-Newark-Nassau Suffolk & 215.5 & $31.1 \%$ \\
\hline San Francisco-Oakland & 100.2 & $16.9 \%$ \\
\hline Washington & 87.7 & $15.8 \%$ \\
\hline Boston & 81.2 & $13.2 \%$ \\
\hline Honolulu & 80.8 & $8.5 \%$ \\
\hline Philadelphia-Wilmington & 74.4 & $9.9 \%$ \\
\hline Chicago & 65.0 & $12.6 \%$ \\
\hline Los Angeles & 55.7 & $6.3 \%$ \\
\hline Seattle & 55.0 & $8.7 \%$ \\
\hline Portland & 49.0 & $6.5 \%$ \\
\hline Miami-Fort Lauderdale & 46.2 & $3.7 \%$ \\
\hline West Palm Beach & 46.2 & NA \\
\hline Baltimore & 41.4 & $7.6 \%$ \\
\hline \multicolumn{3}{|c|}{ Places with more than 20 but less than 40 passenger trips per capita } \\
\hline Las Vegas & 39.8 & $4.2 \%$ \\
\hline Denver & 38.2 & $5.2 \%$ \\
\hline Salt Lake City & 37.6 & $3.3 \%$ \\
\hline San Diego & 33.4 & $3.8 \%$ \\
\hline Atlanta & 30.0 & $4.0 \%$ \\
\hline Cleveland & 29.2 & $5.1 \%$ \\
\hline Minneapolis & 27.7 & $5.3 \%$ \\
\hline San Jose & 24.1 & $3.5 \%$ \\
\hline Austin & 21.3 & $4.0 \%$ \\
\hline St. Louis & 20.2 & $3.3 \%$ \\
\hline \multicolumn{3}{|c|}{ Places with fewer than 20 passenger trips per capita } \\
\hline Tuscon & 18.8 & $2.8 \%$ \\
\hline Houston & 17.9 & $3.1 \%$ \\
\hline Sacramento & 17.1 & $2.7 \%$ \\
\hline Phoenix & 15.8 & $3.0 \%$ \\
\hline Cincinati & 14.1 & $3.6 \%$ \\
\hline Hartford & 13.6 & $3.5 \%$ \\
\hline Dallas-Fort Worth & 13.4 & $2.0 \%$ \\
\hline Orlando & 12.8 & $2.3 \%$ \\
\hline Charlotte & 12.4 & $2.7 \%$ \\
\hline Stamford & 11.7 & $9.9 \%$ \\
\hline Albuquerque & 11.5 & NA \\
\hline Detroit & 11.1 & $1.8 \%$ \\
\hline Tampa & 9.4 & $1.6 \%$ \\
\hline Jacksonville & 8.6 & $1.3 \%$ \\
\hline Columbus & 8.5 & $2.3 \%$ \\
\hline Kansas & 8.0 & $1.7 \%$ \\
\hline Nashville & 6.0 & $1.7 \%$ \\
\hline Indiannapolis & 5.6 & $1.0 \%$ \\
\hline Riverside & 5.6 & $1.9 \%$ \\
\hline Mean & 36.2 & $5.8 \%$ \\
\hline
\end{tabular}


makes possible a much greater concentration of office space in the CBD than high auto use for the journey to work, although that link is ambiguous. Note that Los Angeles and Seattle have about the same above-average per-capita passenger trips: 55 (Table 2). Yet Los Angeles has a far lower share of its office space in the CBD than Seattle: less than 14 percent compared with 50 percent (Table 1). That connection, along with the link to efficiency as measured by rents, is explored in the following sections.

\section{$4 \quad$ Panel regression model and data}

In panel regression (the technique used here) the data are for multiple entities, 118 real estate markets, observed for two or more years (17 years in this case). That means the maximum total observations are 2006 (i.e., 17 x 118). Because of some missing values for some years, our full sample is somewhat less than that. Panel data are a result of pooling cross-section data with time-series data. The key advantage is to greatly increase the sample size from what it would be with only cross-section data or only time-series data.

Our approach to estimating the effects of public transit use on the unobserved urban agglomeration economies-the efficiency of a metropolitan area-is to regress office rents (our measure of efficiency) on per-capita public transit use and other variables that influence office rents. A positive, significant coefficient on the per-capita public transit use variable would be interpreted as the separate effect of transit use on office rents. In other words, it would measure the contribution, if any, of public transit use to urban agglomeration economies (efficiency).

In developing the model we hoped to specify a structural equation from which we would derive a viable estimating equation, as in the recent article on agglomeration economies arising from office activities (Drennan and Kelly 2011). We wanted all the variables in our estimating equation to be annual changes (first differences) rather than levels in order to avoid the twin econometric problems of omitted variable bias (the omission of a variable that affects rents but is constant over time, such as building codes and zoning laws) and nonstationery variables (a variable with a time trend which, when included, leads to biased results). Levels of economic variables most often have time trends, whereas changes in variablesfirst differences - usually do not. It was not possible to develop a structural equation primarily because in estimating equations, our key variable - per-capita transit use-is never statistically significant in first-difference form. In future work we hope to correct that shortcoming by utilizing some other measure of transit use such as passenger miles traveled or revenue miles. Our final estimating equation is:

(1) $(\text { D. Irent })_{\mathrm{it}}=\mathrm{b} 1(\text { lpctrips })_{\mathrm{it}}+\mathrm{b}_{2}(\text { D. lvacrate })_{\mathrm{it}-1}+$
$\mathrm{b}_{3}\left(\right.$ vaclessnat $_{\mathrm{it}-1}+\mathrm{b}_{4}(\text { D. ldemand })_{\mathrm{jt}}+\mathrm{b}_{5}(\text { lusunrate })_{\mathrm{t}}+\mathrm{u}_{\mathrm{it}}$

The D represents first differences of logs, which approximates percentage changes, of a variable. The prefix 1 represents the logs, base e, of a variable. The left-hand variable is annual change in the log of real office rent (equivalent to percent change) in market area (i) ( $\mathrm{i}=1 \ldots . .118)$ and year $\mathrm{t}(\mathrm{t}=1991-$ 2007). The first right-hand variable is the log of per-capita public transit use (lpctrips) in UZA (j) and year (t). That variable varies by UZA ( $\mathrm{j}$ ) and not by market area (i). The next variable, D.lvacrate, is the annual change in the log of the office vacancy rate in market area (i) and year $(\mathrm{t})$. The third right-hand variable, vaclessnat, is the difference between the observed vacancy rate in market area (i) and year $(\mathrm{t})$ and the natural vacancy rate in the market area (i). The equilibrium, or natural, vacancy rate is unobserved. We use the 21-year mean (1987-2007) vacancy rate in each of the 118 market areas as the estimated natural vacancy rate. That is the only variable not in $\log$ form because many of the observations are negative and therefore would be undefined in $\log$ form. Given that the office market literature assigns an important role to the lagged natural vacancy rate

Table 3: Descriptive statistics full sample, 2007.

\begin{tabular}{|c|c|c|c|c|c|}
\hline Variable & Observations & Mean & $\begin{array}{l}\text { Standard } \\
\text { Deviation }\end{array}$ & Minimum & Maximum \\
\hline Real gross rent per square foot & 118 & $\$ 23.86$ & $\$ 7.51$ & $\$ 11.59$ & $\$ 67.78$ \\
\hline $\begin{array}{c}\text { Annual per capita passenger } \\
\text { trips }\end{array}$ & 42 & 36.1 & 38.0 & 5.6 & 215.5 \\
\hline Vacancy rate & 118 & $13.5 \%$ & $4.3 \%$ & $2.4 \%$ & $26.0 \%$ \\
\hline Vaclessnat & 118 & -1.8 & 3.7 & -14.1 & 9.0 \\
\hline Demand, mil. sq. ft. & 118 & 24.9 & 37.5 & 1.2 & 346.5 \\
\hline $\begin{array}{c}\text { Producer service employment, } \\
\text { thou. }\end{array}$ & 42 & 421 & 367.5 & 76 & 1849 \\
\hline Percent space in CBD & 42 & $32.5 \%$ & $15.2 \%$ & $5.4 \%$ & $77.6 \%$ \\
\hline
\end{tabular}


in rent adjustment, we include that variable lagged one year. D.ldemand is the annual change in the log of office demand in market area (i) and year ( $\mathrm{t}$ ). Demand is defined as market area office supply, a TWR published value, minus that share of supply that is vacant. The last right-hand variable is the log of the US unemployment rate in year $(\mathrm{t})$. It is included because metropolitan office rents are highly cyclical (Drennan and Kelly 2010). The u represents the error term.

Table 3 defines the variables and presents descriptive statistics for 2007, most of which are included in our regressions. The number of observations is either 118 for market area variables or 42 for UZA variables. Because every UZA has two or more market areas (except Riverside), the UZA-wide variables are repeated for each market area in the regressions.

\section{$5 \quad$ Panel Regression Results}

Table 4 presents our estimated panel regression equations for all places, for CBDs only, and for suburbs (SUB) only. In each of the three equations, all of the variables have the expected signs-positive for transit ridership and demand; negative for the two vacancy rate variables and the national unemployment rate. They are also all significant—most at the level of 1 percent or better. The overall $\mathrm{R}^{2}$ values are similar: 0.24 to 0.27 . Those are acceptable values for an equation in which the left-hand variable is in first differences. One reason for the significance of all the variables is the large sample sizes, ranging from 1934 for the equation for all places to 743 for the equation for CBDs. Although the coefficient on the transit ridership variable is larger for the CBD equation (+.028) than for the suburbs equation $(+.014)$, the difference between them is not statistically significant (i.e., their 95 percent confidence intervals overlap). Thus, these results support the hypothesis that higher transit use adds to office rents, but they do not support the hypothesis that such use adds more to rents in the CBD than in the suburbs.

Table 5 presents results from the same equation for four different and non-overlapping subsets of our sample: (1) CBDs in UZAs with the percent of space concentrated in the CBD greater than 30 percent, (2) SUBs in UZAs with the percent of space concentrated in the CBD greater than 30 percent, (3) CBDs in UZAs with the percent of space concentrated in the CBD 30 percent or less, and (4) SUBs in UZAs with the percent of space concentrated in the CBD 30 percent or less. This partitioning gets at the question: Do places with high concentrations of space in the $\mathrm{CBD}$ gain more from public transit use than places with low concentrations of space in the CBD? The tentative answer, based on the equations in Table 5, is "Yes." For those CBDs with more than 30 percent of the total UZA office space, the positive coefficient on the transit use variable is +0.046 , and it is significant at the 1 percent level. For suburbs in those UZAs, the coefficient is also positive and significant at the 1 percent level. Although it is somewhat smaller $(+0.039)$ than the CBD coefficient, the difference between the two is not statistically significant. By contrast, the identical equations for places with low concentration of space (30 percent or less) in the CBD of their UZA yield coefficients on the transit use variables that are close to zero and not statistically significant. Thus, when we partition the sample into four parts: CBDs and suburbs in UZAs with more than 30 percent of their office space in the $\mathrm{CBD}$, and $\mathrm{CBD}$ s and suburbs with 30 percent or less of their office space in the $\mathrm{CBD}$, there is no significant effect of transit use on UZAs with relatively small CBDs. All of the other coefficients in those low-concentration equations have the expected signs, and all but one are statistically sig-

Table 4: Public transit panel regressions, all places, CBDs, and suburbs.

Dependent Variable is log of annual percent change in real gross rent per square foot per year.

\begin{tabular}{cccc} 
Variables & All & CBDs & SUBs \\
\hline Log of annual per capita passenger trips & $+0.015^{*}$ & $+0.028^{*}$ & $-0.014^{*}$ \\
Change in log of vacancy rate, lagged & $-0.074^{* *}$ & $-0.081^{* *}$ & $-0.067^{* *}$ \\
Vacancy rate less natural vacancy rate, lagged & $-0.004^{* *}$ & $+0.455^{* *}$ & $-0.004^{* *}$ \\
Change in log of demand & $+0.430^{* *}$ & $-0.141^{* *}$ & \\
Log of U.S. unemployment rate & $-0.114^{* *}$ & & $-0.091^{* *}$ \\
$\mathrm{R}^{2}$ & & 0.27 & 0.29 \\
Within & 0.28 & 0.23 & 0.07 \\
Between & 0.14 & 0.24 & 0.27 \\
Overall & 0.26 & 743 & 1,191 \\
$\mathrm{n}$ & 1,934 & & \\
\hline
\end{tabular}

\footnotetext{
* Significant at 5 percent level or better.

** Significant at 1 percent level or better.
} 
Table 5: Public transit panel regressions, CBDs, and SUBs with higher concentration of space in the CBD and lower concentrations of space in the CBD.

\begin{tabular}{|c|c|c|c|c|}
\hline & CBDs with \% & SUBs with \% & CBDs with \% & SUBs with \% \\
\hline Variables & space $\mathrm{CBD}>30.0$ & space $\mathrm{CBD}>30.0$ & space $\mathrm{CBD}<30.1$ & space $\mathrm{CBD}<30.1$ \\
\hline Log of annual per capita passenger trips & $+0.046^{* *}$ & $+0.039^{* *}$ & +0.013 & +0.004 \\
\hline Change in log of vacancy rate, lagged & $-0.085^{* *}$ & $-0.074^{*}$ & $-0.066^{* *}$ & $-0.049^{* *}$ \\
\hline Vacancy rate less natural vacancy rate, lagged & $-0.004^{* *}$ & $-0.003^{* *}$ & -0.004 & $-0.004^{* *}$ \\
\hline Change in log of demand & +0.547 & $+0.384^{*}$ & $+0.363^{*}$ & $+0.465^{*}$ \\
\hline Log of U.S. unemployment rate & $-0.151^{* *}$ & $-0.088^{* *}$ & $-0.145^{* *}$ & $-0.115^{* *}$ \\
\hline \multicolumn{5}{|l|}{$\mathrm{R}^{2}$} \\
\hline Within & 0.31 & 0.27 & 0.23 & 0.34 \\
\hline Between & 0.26 & 0.07 & 0.20 & 0.09 \\
\hline Overall & 0.23 & 0.16 & 0.22 & 0.32 \\
\hline $\mathrm{n}$ & 445 & 672 & 303 & 524 \\
\hline
\end{tabular}

* Significant at $5 \%$ level or better.

**Significant at $1 \%$ level or better.

Table 6: Public transit cross-section regressions.

\begin{tabular}{|c|c|c|c|c|c|c|}
\hline Variables & $1991 \mathrm{CBDs}$ & 1991 SUBs & 1999 CBDs & 1999 SUBs & 2007 CBDs & 2007 SUBs \\
\hline $\begin{array}{c}\text { Log of per capita passenger } \\
\text { trips }\end{array}$ & +0.003 & +0.040 & $+0.128^{* *}$ & $+0.085^{* *}$ & $+0.160^{* *}$ & $+0.098^{* *}$ \\
\hline Log of vacancy rate & $-0.440^{* *}$ & -0.290 & $-0.286^{* *}$ & $-0.230^{* *}$ & $-0.281^{*}$ & $-0.472^{* *}$ \\
\hline $\begin{array}{c}\text { Vacancy rate less natural } \\
\text { vacancy rate }\end{array}$ & $+0.032^{*}$ & $+0.031^{*}$ & +0.016 & $+0.018^{*}$ & +0.007 & +0.013 \\
\hline Log of demand & $+0.091^{*}$ & +0.006 & +0.032 & +0.035 & +0.037 & +0.008 \\
\hline Adjusted $\mathrm{R}^{2}$ & 0.3 & 0.08 & 0.54 & 0.45 & 0.44 & 0.36 \\
\hline $\mathrm{n}$ & 44 & 71 & 44 & 71 & 44 & 70 \\
\hline
\end{tabular}

* Significant at 5\% level or better

${ }^{* *}$ Significant at $1 \%$ level or better.

nificant, so it is not an issue of lower $\mathrm{n}$ values than in the high concentration equations.

We also estimated cross-section equations using levels of the variables for all observations rather than first differences. Cross-section of levels avoids the problem of non-stationery variables (i.e., variables that exhibit a time trend and thus can lead to biased regression results). Also, such equations might reveal differences over a long time period in the sensitivity of rents to public transit use. Our panel estimation using first differences excludes the possibility of judging whether such use had weaker, stronger, or constant effects over time on office rents. Separate equations are shown for CBDs and suburbs for three years: 1991, 1999, and 2007 in Table 6. All variables are in $\log$ form except vaclessnat, as before. No variables are lagged. The US unemployment rate variable has been dropped because it does not vary over one year. Sample sizes are small compared with the panel regressions: 44 for the $\mathrm{CBD}$ equations and 71 or 70 for the SUB equations. Not surprisingly, each equation has one to three insignificant variables. The 1991 cross-section equations have positive coefficients on the transit use variable but are not significant. In the 1999 and 2007 equations, the coefficients on the transit use variable are positive and significant. As before, however, 95 percent confidence intervals for those coefficients indicate no significant difference. That is, we cannot infer that the positive effect of high transit use is bigger on rents in the CBDs than in the suburbs. The pattern is similar for 2007. These cross-section equations provide some, albeit weak, support for the proposition that public transit use over the past decade has had a moderately positive effect on metropolitan office rents, with no significant difference between the effect on $\mathrm{CBD}$ rents and suburban rents. That effect is not evident in the 1991 equation. 
One possible problem not dealt with in our estimating equations is that the hypothesized causation from public transit use to office rents, especially in the CBD, may not run just one way. That is, higher priced office space, bespeaking higher demand, may be a cause of enhanced transit use. This is a case of "simultaneous causality (when causality runs backward from $\mathrm{Y}$ to $\mathrm{X}$ [from rent to transit use] as well as forward from X to Y [from transit use to rents])." (Stock and Watson 2007, p. 422) To deal with that possibility, we have estimated two-stage least-squares equations. The right-hand variable that may be endogenous (that is, affected by the rent variable) in our one equation system is the public transit use variable. We tried to find instruments that were correlated with the transit use variable but much less so with the office rent variable. The best instrument available was the average UZA transit fare by year, but that data is available only back to 2002 . Thus, an equation using fare as an instrument had only six years of observations instead of 17, which proved inadequate. The equation we present here uses two instruments: the percent of UZA space in the $\mathrm{CBD}$ and producer service employment (the sum of employment in three NAICS industries: information, finance and insurance, and professional and business services, all of which are heavy users of office space). Both are positively correlated with the transit use variable and much less so with the office rent variable. Ideally, instrumental variables would be uncorrelated with the rent variable. We show the three two-stage least-squares-estimated equations in Table 7 . The first is for all real estate markets, the second for CBD markets, and the third for suburban markets. The first-stage equations of two-stage least squares are shown in the first panel of Table 7 . The transit use variable, lpctrips, is the left-hand variable in the first-stage equations. Then the estimated value from regressing lpctrips on the two instruments plus the exogenous variables in the rent equation (the two vacancy rate variables and the demand variable) is used as a right-hand variable in the second-stage regression. First-stage equations that included the US unemployment rate were unacceptable because that variable was not statistically significant.

In the first-stage equations, the two instrumental variables (the log of percent of UZA office space in the CBD and the $\log$ of producer service employment in the UZA) are statistically significant at the 1 percent level. Of the remaining three variables, only the vacancy rate less the natural vacancy rate, lagged, is significant. The producer service employment coefficient is positive as expected, but the percent of space in the $\mathrm{CBD}$ coefficient is negative, the opposite of expected. $\mathrm{R}^{2}$ values are very low. An $\mathrm{F}$ statistic below 10 indicates a failed first-stage equation. Note that the CBD equation is barely acceptable with an F statistic of 11, while the other two have values of 57
Table 7: Public transit two-stage least-squares panel regressions.

1 st stage variables and regression coefficients.

Instrumented variable is log per capita passenger trips.

\begin{tabular}{cccc}
\hline Variables & All & CBDs & SUBs \\
\hline $\begin{array}{c}\text { Change in log of vacancy } \\
\text { rate, lagged }\end{array}$ & -0.003 & -0.009 & -0.002 \\
Vacancy rate less natural & $-0.008^{* *}$ & $-0.005^{* *}$ & $-0.010^{* *}$ \\
vacancy rate, lagged & & & \\
Change in log of demand & 0.056 & 0.163 & 0.001 \\
Log of percent space in CBD & $-0.270^{* *}$ & $-0.285^{* *}$ & $-0.325^{* *}$ \\
Log of producer service & $+0.233^{* *}$ & $+0.110^{* *}$ & $0.274^{* *}$ \\
employment & & & \\
$\mathrm{R}^{2}$ & & & \\
Within & 0.14 & 0.08 & 0.17 \\
Between & 0.07 & 0 & 0.06 \\
Overall & 0.08 & 0 & 0.08 \\
1st Stage F & 57 & 11 & 46 \\
$\mathrm{n}$ & 1,900 & 693 & 1207 \\
\hline
\end{tabular}

2nd stage variables and regression coefficients.

Dependent variable is annual percent change in real gross rent per square foot per year.

Instrumented variable is log per capita passenger trips. Instruments not included in the 2 nd stage regression are log percent of space in CBD and log producers service employment.

\begin{tabular}{cccc}
\hline Variables & All & CBDs & SUBs \\
\hline $\begin{array}{c}\text { Log per capita passenger } \\
\text { trips, estimated }\end{array}$ & $+0.061^{*}$ & +0.093 & +0.045 \\
$\begin{array}{c}\text { Change in log of vacancy } \\
\text { rate, lagged }\end{array}$ & $-0.073^{* *}$ & $-0.096^{* *}$ & $-0.061^{* *}$ \\
$\begin{array}{c}\text { Vacancy rate less natural } \\
\text { vacancy rate, lagged }\end{array}$ & $-0.006^{* *}$ & $-0.007^{* *}$ & $-0.005^{* *}$ \\
Change in log of demand & $+0.551^{* *}$ & $+0.655^{* *}$ & $+0.506^{* *}$ \\
$\mathrm{R}^{2}$ & & & \\
Within & 0.24 & 0.24 & 0.25 \\
Between & 0.10 & 0.16 & 0.04 \\
Overall & 0.12 & 0.11 & 0.15 \\
$\mathrm{n}$ & 1,900 & 693 & 1,207 \\
\hline
\end{tabular}

* Significant at $5 \%$ level or better.

** Significant at $1 \%$ level or better.

Note: Equations estimated with Stata 10 software, xtivreg function.

and 46.

The second panel of Table 7 presents the second-stage regression results in which the estimated value of the log of per-capita trips, estimated from the first-stage equation, is a right-hand variable in each of the three equations. In the equation for all market areas, the coefficient on the transit use vari- 
able is positive and significant $(+0.061)$. It is not significant in the CBD or the SUB equations. All the other variables in the three second-stage regressions are highly significant, with the expected signs on their coefficients. Given that the purpose of two-stage least squares is to estimate valid coefficients for the instrumented variable (in this case, transit use), these results are disappointing. Only the equation for all real estate markets has a significant coefficient on the transit use variable.

The extreme variation in transit use among UZAs (see Table 2) suggests that our results may be distorted by outliers-places with unusually high per-capita transit use and a high percentage of journeys to work by transit. We tested the robustness of our results by first running the same set of equations with New York omitted from the sample, and then with the five top places omitted from the sample (New York, San Francisco, Washington, DC, Boston, and Chicago). We did not repeat the cross-section equations or the two-stage leastsquares equations. Rather than show the seven equations of Tables 4 and 5 again without those high-transit use places, Table 8 shows the estimated coefficients on the log of the per-capita transit use variable from the original equations, from the equations excluding New York, and from the equations excluding all five high-transit-use places. As shown, the similarity-in fact, the lack of significant difference among the original coefficients and the coefficients of the two new samples-argues that our results are robust to excluding outliers.

Based on our estimated equations, we can state that public transit use appears to have a positive effect on office rents, our

Table 8: Estimated coefficients on transit use variable from different samples of places.

\begin{tabular}{|c|c|c|c|}
\hline & $\begin{array}{l}\text { Original Esti- } \\
\text { mates, Tables } 4 \\
\quad \& 5\end{array}$ & $\begin{array}{l}\text { Estimates } \\
\text { Excluding } \\
\text { New York }\end{array}$ & $\begin{array}{c}\text { Estimates } \\
\text { Excluding Five } \\
\text { Places (a) }\end{array}$ \\
\hline All places & $+0.015^{*}$ & $+0.015^{*}$ & $+0.017^{* *}$ \\
\hline All CBDs & $+0.028^{*}$ & $+0.027^{*}$ & $+0.033^{* *}$ \\
\hline All SUBs & $+0.014^{*}$ & $+0.014^{*}$ & $+0.016^{*}$ \\
\hline $\begin{array}{c}\text { CBDs with CBD } \\
\text { space }>30.0 \%\end{array}$ & $+0.046^{* *}$ & $+0.045^{* *}$ & $+0.053^{* *}$ \\
\hline $\begin{array}{c}\text { SUBs with CBD } \\
\text { space }>30.0 \%\end{array}$ & $+0.039^{* *}$ & $+0.046^{* *}$ & $+0.054^{* *}$ \\
\hline $\begin{array}{c}\text { CBDs with CBD } \\
\text { space }<30.1 \%\end{array}$ & +0.013 & +0.013 & +0.013 \\
\hline $\begin{array}{c}\text { SUBs with CBD } \\
\text { space }<30.1 \%\end{array}$ & +0.004 & +0.004 & +0.004 \\
\hline
\end{tabular}

(a) The five places are New York, San Francisco, Boston, Chicago, and Washington.

* Significant at $5 \%$ level.

${ }^{* *}$ Significant at $1 \%$ level.

Note: Equations estimated with Stata 10 software, xtreg function. measure of economic efficiency. That is especially the case for places with higher (above 30 percent) concentrations of office space in the CBD. But that raises the questions: How big is the effect and does it have any implications for expanding public transit? To directly address those questions, we estimated a separate panel regression in which the dependent variable is the log of the level of office rents rather than the difference of logs. All of the right-hand-side variables are also logs of levels, rather than first differences of logs as in the original equations. Thus, the coefficient on the log of per-capita transit use can be interpreted as the elasticity of transit use with respect to office rents. An estimate of that elasticity provides a rough measure of what a change in transit use would do to office rents, ceteris paribus. Given that our best results are for CBDs with more than 30 percent of the UZA office space concentrated in the CBD, we estimated the elasticity equation for $\mathrm{CBD}$ markets in which the percent of UZA office space concentrated in the CBD exceeds 30 percent. The resulting coefficient on the transit use variable is the estimated elasticity. Although the estimate was positive as expected $(+0.052)$, it was not significant. However, the original equation for $\mathrm{CBDs}$ with more than 30 percent of office space concentrated in the $\mathrm{CBD}$ has a coefficient on the same transit use variable of +0.046 and is significant at the 1 percent level.

Given how close the two coefficients are, 0.052 versus + 0.046 , we used the estimated elasticity of +0.046 to roughly measure the effect of increased transit use on office rents. A 1 percent rise in transit use would raise office rents 0.05 percent, ceteris paribus. A 10 percent rise in transit use would raise office rents 0.5 percent, ceteris paribus. Those are tiny effects. Using the mean office rent for 2007 in all markets of $\$ 23.86$ per sq. $\mathrm{ft}$.(see Table 3), those percentage changes translate into rent gains of $\$ 0.12$ to $\$ 0.01-$ from negligible to virtually zero. The policy implication is that efficiency gains from marginal expansion of mass transit would be a tiny fraction of the cost. Nonetheless, places with high transit use and strong concentrations of office space in the CBD may protect office rent premiums over competing suburban locations by maintaining levels of service. The five high-transit-use places noted above have much higher $\mathrm{CBD}$ rents than their suburbs, and that $\mathrm{CBD}$ premium has not been shrinking (Figure 1). In the latest year, 2007, the $\mathrm{CBD}$ average rent of those five places was $\$ 42$ compared with $\$ 26$ for the suburbs. Figure 2 shows CBD and suburban office rents for all other UZAs (37) in our sample. Note that in the past there was a premium for CBD space, but it disappeared around 1995. In fact, since 2005 suburban rents are somewhat higher (about \$1) than CBD rents. 


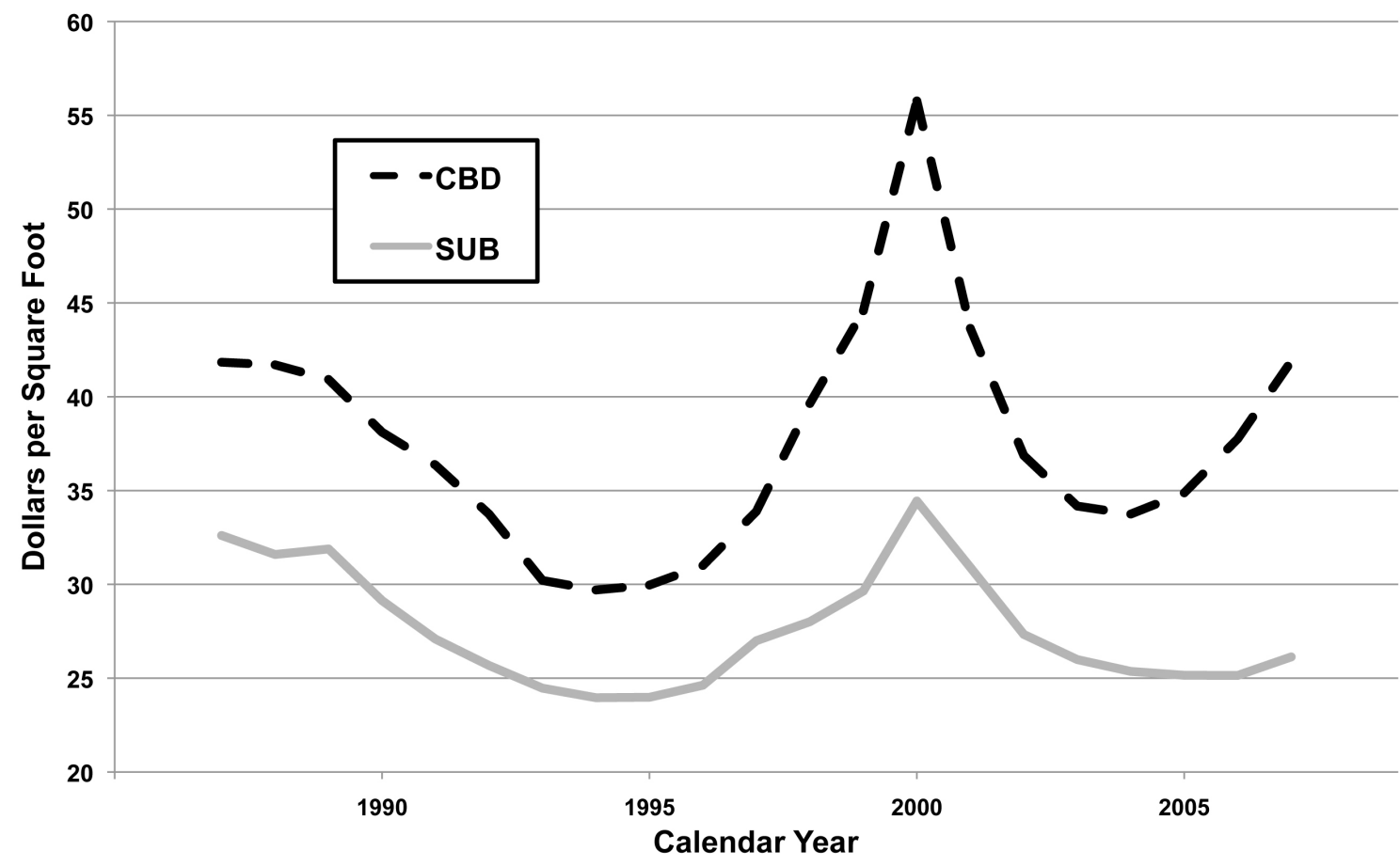

Figure 1: Office rents per square foot five highest transit use UZAs, CBDs, and suburbs.

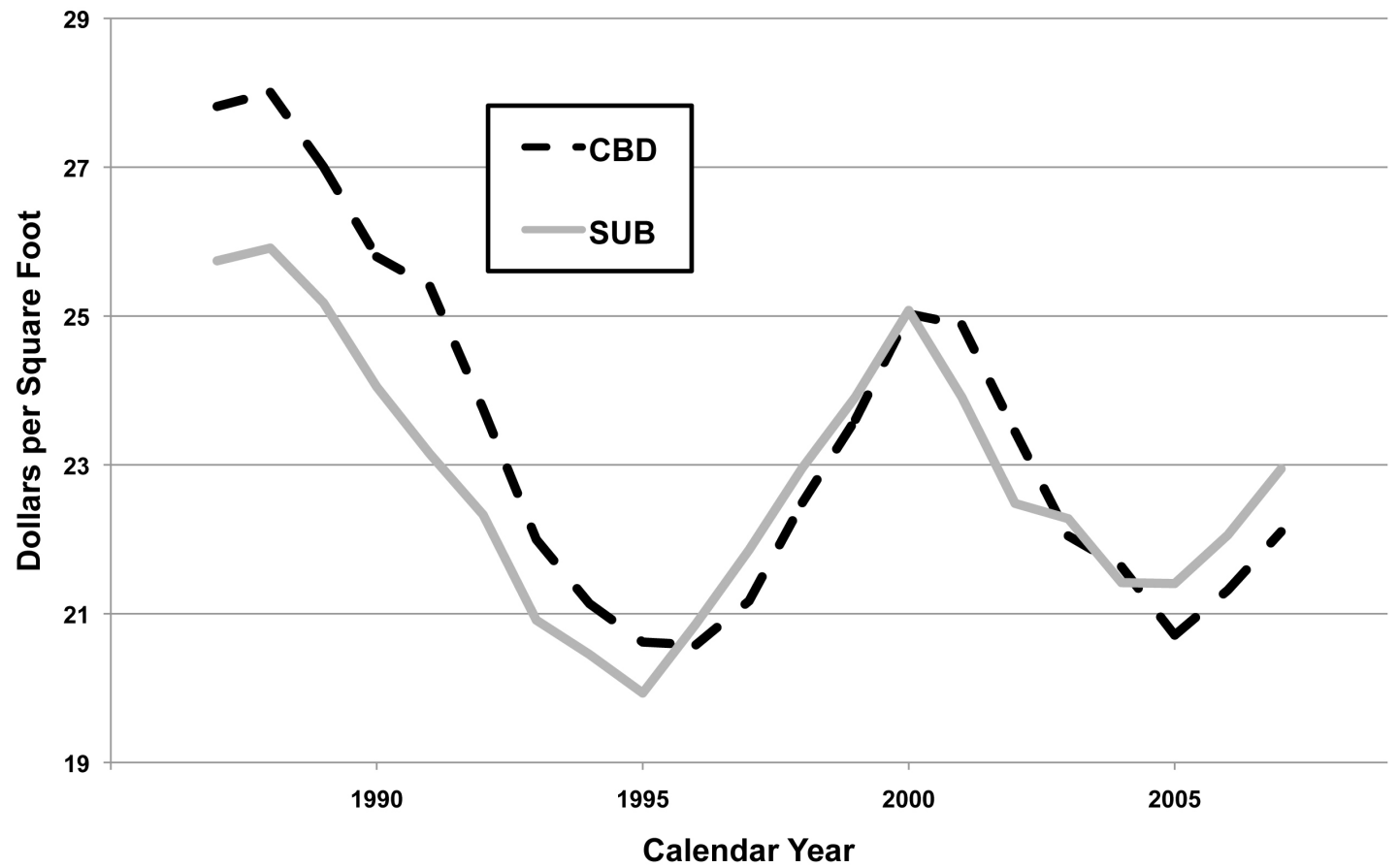

Figure 2: Office rents per square foot, all other UZAs, CBDS, and suburbs. 


\section{Conclusion}

Based on the econometric evidence for 42 of the largest urbanized areas of the United States, there appears to be a positive link between the scale of public transit use and commercial office rents. Arguing here that office rents manifest benefits of agglomeration, we infer that in some places public transit use contributes to urban economic efficiency. The positive link is no stronger for $\mathrm{CBD}$ office markets than for suburban ones (see Table 4), but the link is present for both $\mathrm{CBD}$ and suburban markets in those UZAs with a high concentration (over 30 percent) of office space in the CBD. Evidence of such a link is absent from real estate markets, CBD or suburban, in UZAs with a low concentration of office space (30 percent or lower) in their CBDs (see Table 5).

Cross-section equations for the earliest year, 1991, indicate no link or even a negative link between transit use and office rents. That may be tied to the depressed office market through most of the nation in that recession year. Cross-section results for 1999 and 2007, definitely not recession years, indicate a positive link between transit use and office rents in both CBD and suburban real estate markets. However, as with our panel regressions, there is no significant difference between the effect of transit use on office rents in CBDs and on office rents in suburbs (see Table 6). These results do not reveal a premium for CBD rents over suburban rents attributable to transit use.

The two-stage least-squares equation results are disappointing. The equation for all places has a positive significant coefficient on the estimated transit use variable. That coefficient in the separate CBD and suburban equations is positive but insignificant.

What do these results indicate for public policy with regard to public transit expansion in large urban areas? The message we do not derive from our analysis is that urban areas with a high concentration of office space in their CBDs may be expected to achieve substantial gains in economic efficiency from the expansion of public transit. The estimated effect of higher per-capita ridership on office rents is tiny $(+0.5$ percent $)$ to vanishing $(+0.05$ percent). Nonetheless, places with high transit use and a strong concentration of office space in the CBD may protect office rent premiums over competing suburban locations by maintaining levels of service and required capital investment.

One shortcoming of this analysis is that our per-capita transit use variable is not expressed in first-difference form in our panel regression equations as are most of the other variables. That compromises one advantage of employing panel regression, namely, eliminating the place-fixed effects (zoning laws, building codes, topography, etc.) that can lead to biased results. Further work should employ other measures of transit use such as passenger miles traveled or revenue miles in firstdifference form.

Another possible flaw in our analysis is that we have aggregated the transit use for all transit agencies within each UZA to produce one transit use variable for each UZA. The separate real estate market rents may be affected only by the transit agencies serving that market. It is not clear how we might address that possible problem in future work.

Perhaps most importantly, these results should be interpreted as preliminary rather than definitive. The results may change, perhaps indicating greater impacts for transit services, if additional factors are taken into account. As noted earlier, the likely significant effect of the cost of auto use as reflected in parking pricing has not been taken into account. Similarly, fare policies for transit services in the urban areas also can be better incorporated in the models. Stronger results might be derived by having public transit fare data available for the full NTD sample period- that is, back to 1991. Transportation researchers know that prices matter, as do all economists. We have been told by staff at the NTD that it is possible to construct such a fare series back to 1991, building it up from the annual transit agency fare revenue data that they have. Additional research in this important area may be fruitful in terms of its policy implications.

\section{Funding}

This research was funded in part by the UCLA Ziman Center for Real Estate.

\section{References}

Bollinger, C. R., K. R. Ihlanfeldt, and D. R. Bowes.1998. Spatial variation in office rents within the Atlanta region. Urban Studies, 35(7):1097-1118. doi:http://usj.sagepub. com/content/35/7/1097. 10.1080/0042098984501.

Bureau of Economic Analysis, U.S. Department of Commerce. 2008a. Local area personal income, 1987-2006. Web. http://www.bea.gov/regional/reis/.

Bureau of Economic Analysis, U.S. Department of Commerce. 2008b. National income and product accounts, GDP price index, $2000=100$. web. http://www.bea.gov/ national/nipaweb/index.asp.

Bureau of Labor Statistics, U. S. Department of Labor. 2008. State and area employment, hours, and earnings. Web. http://data.bls.gov/pdq/querytool.jsp?survey=sm.

Cervero, R. 1994. Land market impacts of urban rail tran- 
sit and joint development: An empirical study of rail transit in Washington, D.C. and Atlanta. Journal of the American Planning Association, 60(1):83-94.doi: 10.1080/01944369408975554. http://www.tandfonline. com/doi/abs/10.1080/01944369408975554.

Cervero, R. and M. Duncan. 2002a. Land value impacts of rail transit services in Los Angeles County. Technical report, National Association of Realtors and Urban Land Institute. www.realtor.org/government_affairs/smart_growth/land_ value_impacts.

Cervero, R. and M. Duncan. 2002b. Land value impacts of rail transit services in San Diego County. Technical report, National Association of Realtors and Urban Land Institute. www.realtor.org/government_affairs/smart_growth/ land_value_impacts.

Cervero, R. and M. Duncan. 2002c. Transit's value-added effects: Light and commuter rail services and commercial land values. Transportation Research Record, 1805:8-15. doi: 10.3141/1805-02. http://trb.metapress.com/content/ 1832g82m232t4818/.

Debrezion, G., E. Pels, and P. Rietveld. 2007. The impact of railway stations on residential and commercial property value : A meta-analysis. The Journal of Real Estate Finance and Economics, 35(2):161-180. doi: 10.1007/s11146007-9032-z.

Drennan, M. P. 2002. The information economy and American cities. Baltimore, MD: Johns Hopkins University Press.

Drennan, M. P. and H. F. Kelly. 2011. Measuring urban agglomeration economies with office rents. Journal of Economic Geography, 11(3):481-507. doi: 10.1093/jeg/ lbp066. http://joeg.oxfordjournals.org/content/11/3/481.

Eberts, R. W. and D. P. McMillen. 1999. Handbook of regional and urban economics : Applied urban economics, volume 3 of Handbooks in economics, 7, chapter Agglomeration economies and urban public infrastructure. Amsterdam, Netherlands: North-Holland.

Federal Transit Administration. National transit database. http://www.ntdprogram.gov/ntdprogram/.

Landis, J. D. and D. Loutzenheiser. 1995. BART@20: BART access and office building performance. Working paper 648, Institute of Urban and Regional Development, University of California at Berkeley.

Landis, J. D., University of California at Berkeley, Institute of Urban and Regional Development.1995. Rail transit investments, real estate values, and land use change: A comparative analysis of five California transit systems. Monograph 48. University of California at Berkeley, Institute of Urban and Regional Development.

Marshall, A. 1920. Principles of economics. London, England:
Macmillan.

Owen, D. 2009. Green metropolis : Why living smaller, living closer, and driving less are keys to sustainability. New York, NY: Riverhead Books.

Rosenthal, S. S. and W. C. Strange. 2004. Handbook of regional and urban economics. Vol. 4, Cities and Geography Chapter. Evidence on the nature and sources of agglomeration economies. Handbooks in economics. Elsevier NorthHolland.

StataCorp. 2007. Stata statistical software : Release 10. software; College Station, TX. http://www.stata.com/support/ faqs/res/cite.html.

Stock, J. H. and M. W. Watson. 2007. Introduction to econometrics. Addison-Wesley series in economics. Pearson/Addison Wesley, 2nd edition.

Taylor, B. D., D. Miller, H. Iseki, and C. Fink. 2009.Nature and/or nurture? analyzing the determinants of transit ridership across us urbanized areas. Transportation Research Part A: Policy and Practice,43(1):60-77. doi: 10.1016/j. tra.2008.06.007. http://www.sciencedirect.com/science/ article/pii/S0965856408001274.

Torto Wharton Research. 2008. Torto Wharton research: Real estate markets data file, 4th quarter, 1987-2007. http:// www.cbre.ca/EN/Research/TortoWheatonResearch.htm.

U. S. Census Bureau. 2008. Population estimates for metropolitan statistical areas. http://www.census.gov/popest/ datasets.html. 